\section{Spontaneous Autotetraploidy and Its Impact on Morphological Traits and Pollen Viability in Solanum aethiopicum}

\author{
Hamidou F. Sakhanokho ${ }^{1,2}$ \\ USDA-ARS, Thad Cochran Southern Horticultural Laboratory, 810 Highway \\ 26 West, Poplarville, MS 39470
}

\author{
M. Nurul Islam-Faridi ${ }^{1}$ \\ USDA-Forest Service, Southern Institute of Forest Genetics, Forest Tree \\ Molecular Cytogenetics Laboratory, Texas A\&M University, College \\ Station, TX 77843
}

Additional index words. polyploidy, scarlet eggplant, somaclonal variation

\begin{abstract}
We report for the first time the incidence of spontaneous autotetraploidy in Solanum aethiopicum (PI 636107). Stomatal dimensions and frequency, number of chloroplasts per guard cell, flow cytometry, and chromosome counts were used to differentiate the diploid plants from tetraploids. The impact of increased ploidy on pollen viability as assessed by in vitro germination and on selected morphological traits was evaluated. In vitro pollen germination was reduced in tetraploid plants, but no significant differences were found in fruit production per plant between diploid and tetraploid plants. Compared with the diploids, the tetraploid plants were significantly shorter and had wider leaves and smaller fruits; therefore, tetraploid $S$. aethiopicum plants can be valuable for future breeding programs, particularly those aiming to develop shorter, more compact plants. Moreover, some $S$. aethiopicum selections are grown for their edible leaves, so tetraploid plants producing large leaves would be desirable. Additionally, the availability of tetraploid $S$. aethiopicum could remove hybridization barriers caused by ploidy differences with other tetraploid Solanum species.
\end{abstract}

Solanum aethiopicum is a member of the family Solanaceae and native to Africa. Cultivated S. aethiopicum is the result of a domestication process involving hybridization of its ancestors, Solanum anguivi and the semidomesticated Solanum distichum (Lester and Seck, 2004). S. aethiopicum is also known as scarlet eggplant, "Ethiopian eggplant," "pumpkin on a stick," or "mock tomato." The fruits, leaves, shoots, and roots of S. aethiopicum are used for both food and medicinal purposes with the specific uses depending on the locality and plant type (Adneniji et al., 2012; Lester and Seck, 2004; Sunseri et al., 2010). For example, immature fruits of $S$. aethiopicum are used as cooked vegetables or sometimes eaten raw. The leaves and shoots can also be used as cooked vegetables, whereas fruits, leaves, and roots of bitter cultivars are used

\footnotetext{
Received for publication 7 Apr. 2014. Accepted for publication 25 June 2014.

We are grateful to Carrie Witcher and Kermis Myrick for technical assistance.

Mention of a trademark or proprietary product does not constitute a guarantee or warranty of the product by the U.S. Department of Agriculture and does not imply its approval to the exclusion of other products that may also be suitable.

${ }^{1}$ These authors contributed equally.

${ }^{2}$ To whom reprint requests should be addressed; e-mail Sakhanokho@ars.usda.gov.
}

as medicine in many African countries to treat ailments ranging from colic to high blood pressure (Adneniji et al., 2012; Lester and Seck, 2004; Sunseri et al., 2010). S. aethiopicum has four cultivar groups, Gilo, Kumba, Shum, and Aculeatum, which are defined by specific plant characteristics and environmental growing requirements (Daunay et al., 1995). Cultivars of the Aculeatum group are used as ornamentals (Daunay et al., 1995; Lester et al., 1981), and those of both the Gilo and Aculeatum groups have shown tolerance to pathogens such as as Fusarium oxysporum f. sp. melongenae, a worldwide soilborne disease of eggplant, and Ralstonia solanacearum (Daunay et al., 1991; Hebert 1985; Rizza et al., 2002; Toppino et al., 2008) and Pseudomonas solanacearum (Ano et al., 1991). The plants are also drought- and heat-tolerant (Lester et al., 1981).

Accessions of $S$. aethiopicum were obtained from the U.S. Department of Agriculture (USDA) National Germplasm System for a project initially aimed at assessing intraspecific genetic diversity and screening of $S$. aethiopicum genotypes for their tissue culture potential through shoot apex culture and somatic embryogenesis. Among the clonally propagated plants through shoot, apex of one the accessions (PI 636107) was a single plant that was morphologically different from all the rest. This particular plant had unusually large leaves, suggesting that it might have undergone spontaneous autopolyploidization. $S$. aethiopicum has a basic chromosome number of $x=12$ (Anaso, 1991; Daunay et al., 1993), and cultivars and accessions of all four groups appear to be diploid $(2 n=2 x=$ 24). The effect of induced polyploidy has been associated with modifications of various traits including plant height, flower size, pollen viability, fruit characteristics, and leaf size (Chen et al., 2006; Kermani et al., 2003; Viehmannova et al., 2012; Wu et al., 2012). However, no report of how induced or spontaneous polyploidy affects $S$. aethiopicum growth and reproduction is available. Therefore, the purpose of this study was to confirm the tetraploid $(2 n=4 x=48)$ nature of the suspected polyploid plant by comparing control diploid $(2 n=2 x=24)$ plants with the suspected tetraploid $(2 n=4 x=48)$ cytotype using flow cytometry analysis, stomatal dimensions, chloroplast numbers, and chromosome counts and assess the impact of spontaneous autotetraploidy on pollen viability as determined by in vitro germination and on selected morphological traits including plant height, leaf size, fruit number, fruit dimensions, and weights.

\section{Materials and Methods}

Plant materials. S. aethiopicum (PI 636107) seeds were obtained from the USDA National Germplasm System and germinated in a seed starter mix Sunshine \#3 mix (Sun Gro Horticulture Inc., Bellevue, WA). Each seedling was clonally propagated through in vitro shoot apex culture. The shoot apex $(\approx 1 \mathrm{~cm}$ long) of each seedling was removed, surface-sterilized, and transferred to Murashige and Skoog (1962) (MS) medium supplemented with $2 \%$ sucrose, $8 \mathrm{~g} \cdot \mathrm{L}^{-1}$ agar, and adjusted to $\mathrm{pH}$ 5.8. The MS medium was autoclaved at $121{ }^{\circ} \mathrm{C}$ for $15 \mathrm{~min}$, and the cultures were maintained in petri dishes at $22{ }^{\circ} \mathrm{C}, 50 \%$ humidity, and $16-\mathrm{h}$ days under fluorescent lights with a photon flux averaging $154 \mu \mathrm{moL} \cdot \mathrm{m}^{-2} \cdot \mathrm{s}^{-1}$. As more shoots developed in petri dishes, they were transferred to Magenta jars containing the same MS medium and under the same growth conditions where both diploid and tetraploid plants rooted and developed easily.

Stomatal dimensions, counts, and density. Stomatal length and width were measured using a simple fingernail polish peel technique. The fingernail polish was applied in an $\approx 1 \mathrm{~cm} \times 1 \mathrm{~cm}$ to $1 \mathrm{~cm} \times 2-\mathrm{cm}$ patch on both the abaxial and adaxial surfaces of two leaves of three randomly chosen plants from each of the two cytotypes. The fingernail polish was removed by placing clear tape over the dried polish patches and peeling both the polish and tape off of the leaf. The tape was then affixed to a microscope slide and the section viewed under an Olympus BX43 (Olympus America, Center Valley, PA) microscope using bright field illumination. One field of view was observed on each of the abaxial and adaxial leaf peels. An image was captured of the representative field of view using an 
Olympus DP73 (Olympus America) attached camera with an adapter. The images were evaluated using CellSens Standard 1.7.1 imaging software from Olympus Soft Imaging Solutions (Munster, Germany). Total magnifications of $180 \times$ and $360 \times$ were used to take pictures for counting stomata and measuring the length and width of three stomata per field of view, respectively. The width measurement was made at the widest part of the guard cells of each open stoma and length was made at the longest part of the same stoma. Many leaves had numerous trichomes, which interfered in the leaf peeling process. To avoid damaging the leaf surface, the leaves were carefully and softly abraded using a heavyduty scour pad (3M/Scotch-Brite, St. Paul, $\mathrm{MN})$. Stomatal counts were made under a field of view area of $92,792.53 \mu \mathrm{m}^{2}$ or $0.00092793 \mathrm{~cm}^{2}$ at $180 \times$ total magnification, and stomatal density was determined by dividing the number of stomata per field of view by the area of the field of view. Five randomly chosen plants per cytotype and three leaves per plant were used for stomatal measurements and counts.

Chloroplast counts. A section of fresh leaf was obtained and prepared for fluorescent microscopic observation of guard cells and chloroplasts. A scalpel blade was used to gently shave away most of the pigmented upper part of the leaf to make the guard cells and thus chloroplasts on the bottom portion of the leaf more visible. The slivered leaf was trimmed to $\approx 0.5$ to $1.5 \mathrm{~cm}^{2}$ and placed on a microscope slide. Enough water was added to cover the sample, and a coverslip was applied. The sample was immediately observed under the microscope to avoid drying, which could damage the guard cells. The sample will burn when left in the illumination path for too long, so focusing as well as locating guard cells for photographing was done quickly. Chloroplast counts were performed on five randomly chosen plants from each cytotype. For each plant, two leaves were used, and two samples were prepared from each leaf for chloroplast count. Observations for chloroplast counts were made using the same microscope as described previously for stomatal parameter determination.

Flow cytometry analysis. Ploidy analysis was performed on both control plants and progeny of the suspected tetraploid using flow cytometry. Young, unexpanded leaf tissues were collected from the two cytotypes, and a piece of leaf tissue $\approx 1 \mathrm{~cm}^{2}$ was chopped with a double-edged razor blade in a petri dish containing nuclei extraction buffer. Buffers were supplied as part of the Cystain ultraviolet Precise P Staining Kit (Partec, Muenster, Germany). After a 30-s incubation period with gentle agitation, the extract was poured through a $50-\mu \mathrm{m}$ mesh sieve. The DNA fluorochrome, 4'-6 diamidino-2-phenylindole, nucleus staining buffer was added to the extract buffer in a ratio of $3: 1$, and the sample was analyzed immediately for the DNA content of the nuclei. Ten plants were randomly chosen from each cytotype, and sample measurements were replicated three times
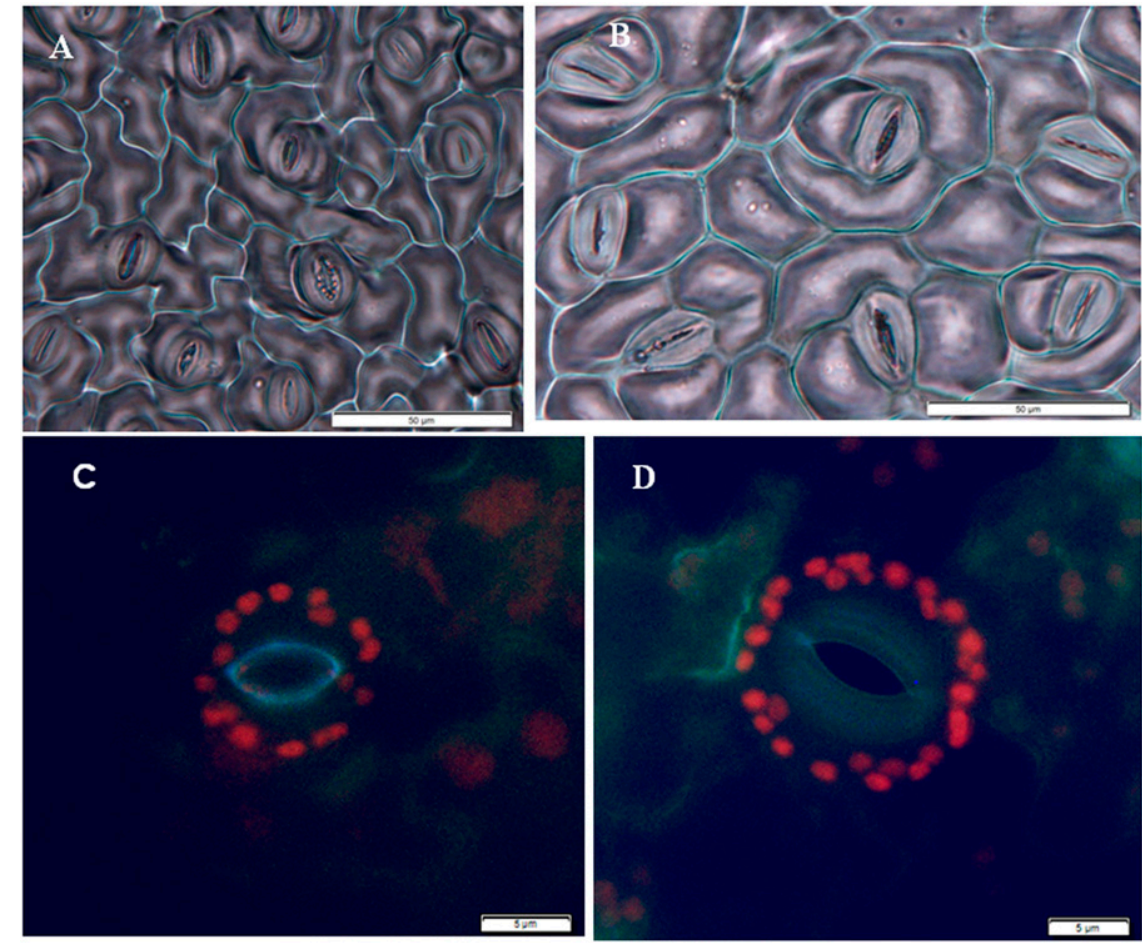

Fig. 1. Comparison between diploid $(2 n=2 x=24)$ and tetraploid $(2 n=4 x=48)$ cytotypes of Solanum aethiopicum (PI 636107) for stomatal dimensions (A-B) and chloroplast counts (C-D). Diploid (A) plants had more stomata than tetraploid (B) plants whose stomata were larger. In contrast, diploid (C) plants had fewer chloroplasts per guard cell than the tetraploid (D) plants. Bar $=50 \mu \mathrm{m}$ for $\mathbf{A}$ and $\mathbf{B}$ and bar $=5 \mu \mathrm{m}$ for $\mathbf{C}$ and $\mathbf{D} ; 180 \times$ total magnification

for each plant. Results were displayed as histograms showing the number of nuclei grouped in peaks of relative fluorescence intensity, which is proportional to DNA content. To determine the standard peak of diploid cells (2C DNA), leaf tissues were collected from the diploid cytotype or control plants. Instrument gain was adjusted so that the peak of nuclei isolated from control plants was set at channel 50, and this calibration was checked periodically to minimize variation resulting from runs. Therefore, peaks representing nuclei from samples with diploid and tetraploid levels were expected to occur at channels 50 and 100 , respectively.

Chromosome counts. Chromosome spread preparation was performed as described by Sakhanokho and Islam-Faridi (2013) on both control (diploid) and the suspected mutated plants. Plants were grown in Metro-Mix (Sun Gro Horticulture, Canada Ltd.) potting soils in a greenhouse. Actively growing root tips, $\approx 1 \mathrm{~cm}$ long, were harvested into $0.8 \%$ (v/v) $\alpha$-bromonaphthalene aqueous solution, pre-treated for $2 \mathrm{~h}$ in the dark to accumulate metaphases, and then fixed in 4 ethyl alcohol (95\%): 1 glacial acetic acid. The root tips were then enzymatically processed to prepare chromosome spreads following mostly the method described by Jewell and Islam-Faridi (1994), except that the enzyme solution was modified as follows: $40 \%(\mathrm{v} / \mathrm{v})$ Cellulase (C2730; Sigma), 20\% (v/v) Pectinase (P2611; Sigma), 40\% (v/v) $0.01 \mathrm{M}$ citrate buffer (trisodium citrate-dihydrate and citric acid-monohydrate, $\mathrm{pH} 4.5$ ), $2 \%$ (w/v) Cellulase
RS (SERVA Electrophoresis $\mathrm{GmbH}$ ), 3\% Cellulase R10 (Yakult Pharmaceutical, Japan), 1\% Macerozyme (Yakult Pharmaceutical), and 1.5\% Pectolyase Y23 (Kyowa Chemical, Japan).

Pollen viability as estimated by in vitro germination. Data on pollen viability were collected from April to August on field-grown plants in 2012 and 2013. For pollen viability estimation through in vitro germination, fresh pollen was collected from field-grown plants of the two cytotypes. An in vitro pollen germination test was performed by choosing 10 random plants per cytotype to evaluate pollen viability using the "hanging drop" technique as described by Sakhanokho and Rajasekaran (2010). The liquid germination medium used consisted of $1.2 \mathrm{M}$ sucrose, $0.42 \mathrm{~g} \cdot \mathrm{L}^{-1}$ calcium nitrate $\left[\mathrm{Ca}\left(\mathrm{NO}_{3}\right)_{2}\right], \quad 0.20 \mathrm{~g} \cdot \mathrm{L}^{-1}$ boric acid $\left(\mathrm{H}_{3} \mathrm{BO}_{3}\right), 0.1 \mathrm{~g} \cdot \mathrm{L}^{-1}$ potassium nitrate $\left(\mathrm{KNO}_{3}\right)$, $0.22 \mathrm{~g} \cdot \mathrm{L}^{-1}$ magnesium sulfate $\left(\mathrm{MgSO}_{4} \cdot 7 \mathrm{H}_{2} \mathrm{O}\right)$, and $15 \%(\mathrm{w} / \mathrm{v})$ polyethylene glycol. The cultures were maintained in a room at an ambient temperature of $\approx 22^{\circ} \mathrm{C}$ and 16 -h days under fluorescent lights with a photon flux averaging $8.8 \mu \mathrm{moL} \cdot \mathrm{m}^{-2} \cdot \mathrm{s}^{-1}$. Pollen viability was determined for the two cytotypes by prepping three flowers per plant and evaluating three slide locations per flower. Ten plants per cytotype were used. A germinated pollen grain was defined as any pollen grain with a pollen tube at least as long as the diameter of the pollen. Total number of pollen grains within a field of view was counted and then the percentage of germinated pollens was determined. 

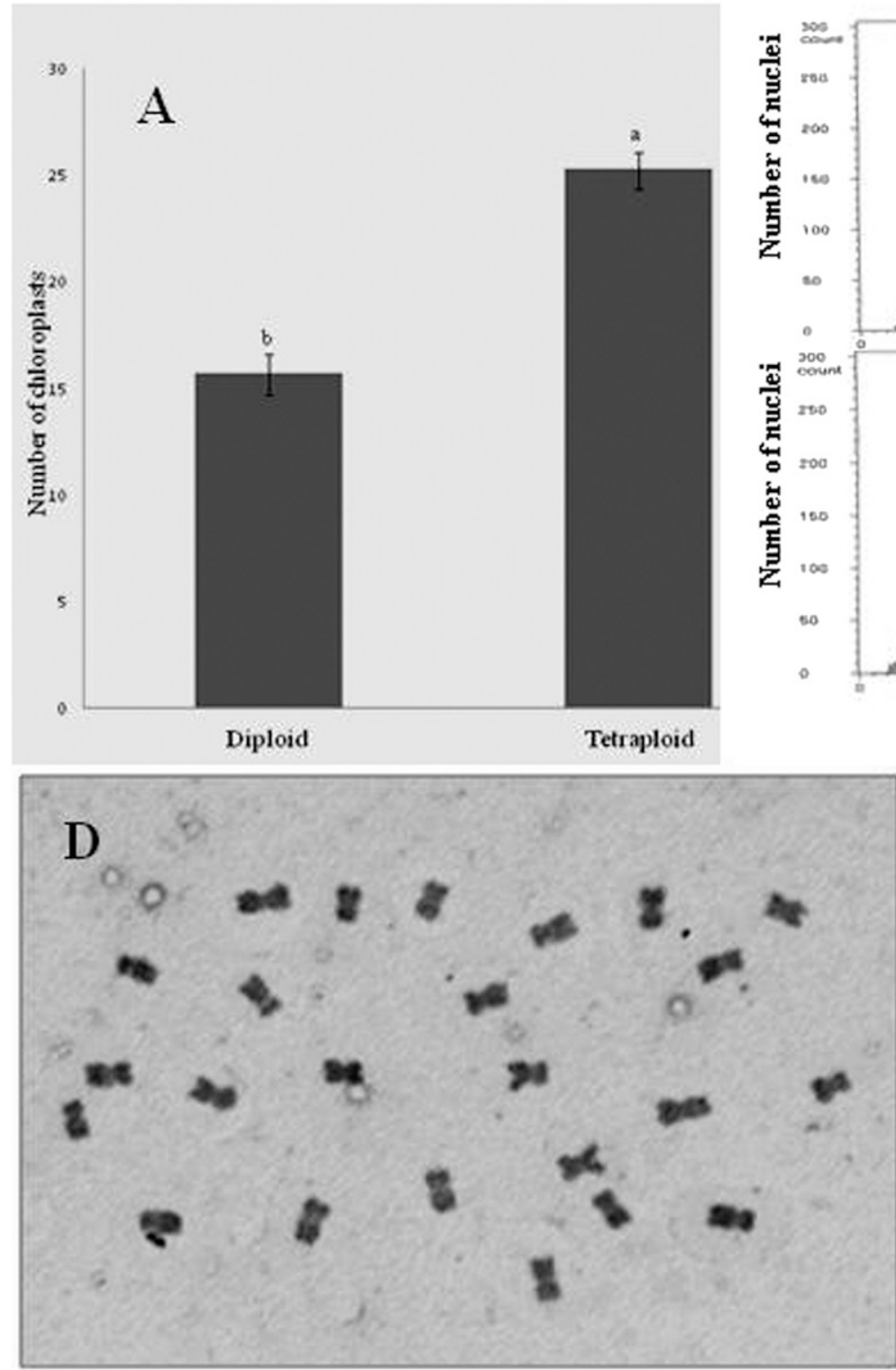

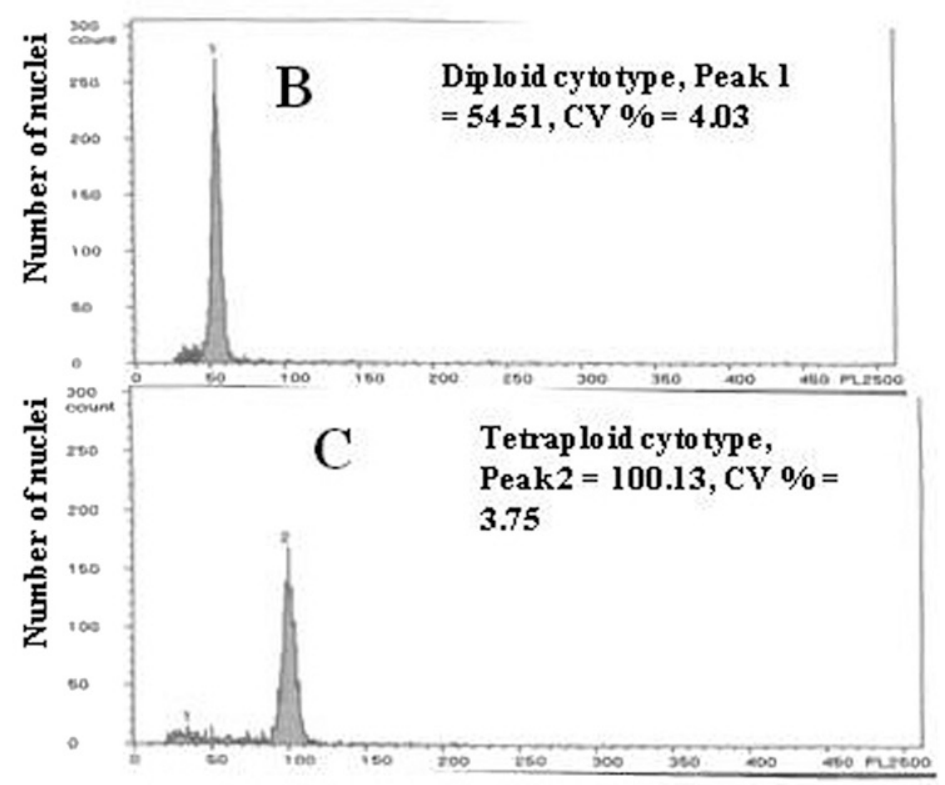

\section{Relative fluor escence}

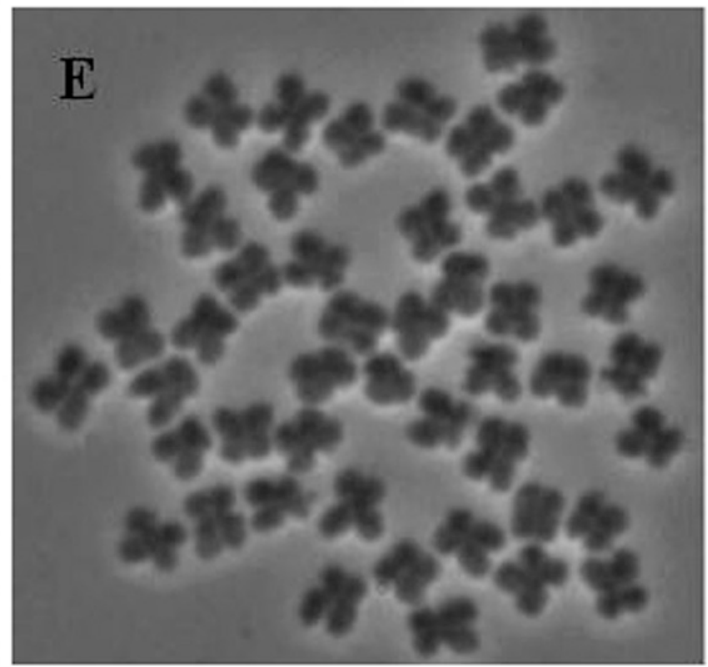

Fig. 2. Comparison between diploid $(2 n=2 x=24)$ and tetraploid $(2 n=4 x=48)$ cytotypes of Solanum aethiopicum (PI 636107). (A) The tetraploid plants had significantly more chloroplasts $(25.33 \pm 0.73)$ per guard cell than the diploid $(15.72 \pm 0.89)$ plants according to $t$ test $(P=0.05)$. Means \pm SE are the results of chloroplast counts performed on five randomly chosen plants from each cytotype. For each plant, two leaves were used, and two samples were prepared from each leaf for chloroplast count. (B-C) Histogram of relative fluorescence intensity of 4',6-diamidino-2-phenylindole (DAPI)-stained of nuclei released from fresh leaves of diploid (B) and tetraploid (C) S. aethiopicum plants. (D) Chromosome counts showing $2 n=2 x=24$ for the control (diploid) S. aethiopicum plants. (E) Chromosome counts showing $2 n=4 x=48$, confirming the tetraploid nature of the tetraploid S. aethiopicum (PI 636107) plant.

Table 1. Comparison between diploid $(2 n=2 x=24)$ and tetraploid $(2 n=4 x=48)$ cytotypes of Solanum aethiopicum (PI 636107) for stomatal width, stomatal length, number of stomata per microscope field of view (per $92,792.53-\mu \mathrm{m}^{2}$ area), and stomatal density (per $0.00092793-\mathrm{cm}^{2}$ area).

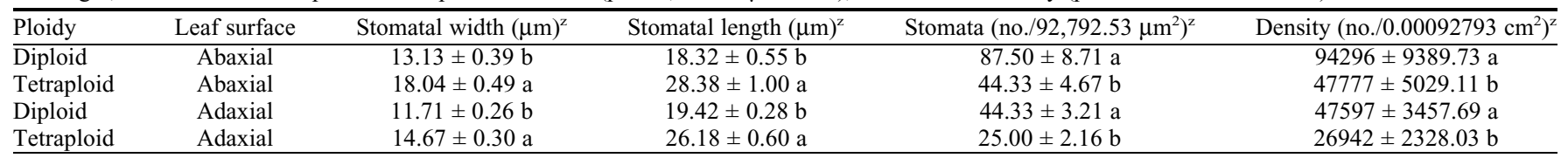

${ }^{2}$ Means within the same column and belonging to the same leaf type (abaxial or adaxial) followed by different letters are significantly different according to $t$ test $(P=0.05)$. Means are the averages of five randomly chosen plants per ploidy level and three leaves per plant for stomatal measurements and counts.

Morphological characterization and statistical analysis. Data on morphological traits were collected from April to August on field-grown plants in 2012 and 2013. Each year, 30 diploid and 30 tetraploid plants were used. Seeds were used to generate a new set of diploid plants, but a new set of tetraploid plants was clonally propagated in vitro and then acclimatized before transfer to the field for the 2013 study. Morphological traits included plant height, leaf length, leaf width, leaf index, fruit numbers, fruit length, fruit circumference, fruit fresh weight, fruit dry weight, and fruit solids percentage. In both 2012 and 2013, new sets of 30 plants per cytotype were grown under field conditions. For leaf measurements, nine leaves were randomly collected from each plant, including three leaves taken from the bottom, middle, and top of the plant, respectively. Mature fruit measurements and weights were recorded for all plants of both cytotypes. Data were analyzed with the $t$ test procedure of SAS (Version 9.1.3; SAS Institute Inc., Cary, $\mathrm{NC})$, and means were compared $(P=0.05)$. 


\section{Results and Discussion}

Ploidy verification. We first used stomatal data and chloroplast counting for ploidy screening. Stomatal size and density per unit leaf area as well as the number of chloroplasts per guard cell have been used to successfully distinguish different ploidy levels among cytotypes (Aryavand et al., 2003; Sari et al., 1999). Although less accurate than chromosome counts and flow cytometry analysis, measuring stomatal size, calculating stomatal density per unit leaf area, and counting chloroplasts can be useful in assessing ploidy. The main advantages of these techniques are that they are faster and less tedious than chromosome counting and less expensive than flow cytometry. Therefore, both methods were used for initial ploidy screenings of the two S. aethiopicum cytotypes (Figs. 1A-D and 2A; Table 1). Irrespective of leaf surface type (adaxial or abaxial), significant $(P=0.05)$ differences were found between the two cytotypes based on stomatal length and width, number of stomata, and stomatal density per microscope field of view area (Table 1). Tetraploid stomata were longer and wider than diploid ones, and in contrast, diploid leaves had more stomata per microscope field of view (per 92,792.53 $\mu^{2}$ area) than tetraploid leaves (Table 1). Furthermore, the tetraploid plants had significantly $(P=0.05)$ more chloroplasts $(25.33 \pm 0.73)$ per guard cell than diploid plants (15.72 \pm 0.89$)$ (Fig. 2). These results agree with reports about other species such as Platanus acerifolia and Lagerstroemia indica (Liu et al., 2007; Zhang et al., 2010). Additionally, we determined the chromosome numbers in root tips collected from both control (diploid) S. aethiopicum (PI 636107) and suspected tetraploid plants (Fig. 2D-E). The chromosome number for the control plants was $2 n=2 \mathrm{x}=24$ (Fig. 2D), which is in accordance with other published studies on S. aethiopicum (Anaso, 1991; Daunay et al., 1993). Chromosome counting also confirmed the tetraploid $(2 n=4 x=48)$ nature of the suspected polyploid plant (Fig. 2E).

Somaclonal variation is variation in regenerated plants that takes place as a result of tissue culture of any type, although some scientists require that this phenomenon be heritable through a sexual cycle (Skirvin et al., 1994), but its origin remains mostly enigmatic (Rodriguez-Enriquez et al., 2011). Several factors contribute to the occurrence of somaclonal variation. Among these factors is pre-existing cytological variation in the explant, in which case the choice of explant may be an important determinant of in vitro cytological variation (Lee and Phillips, 1988). Explant genotype, culture regimes (composition of media, subculture interval, duration of in vitro growth), and regenerative capacity of the cultured cells also contribute to this phenomenon (Bayliss, 1977; Lee and Phillips, 1988; Mahfouz et al., 1983). Recently, however, new hypotheses ranging from epigenetics, variation in DNA methylation patterns, transcriptional activation of specific transposable elements, to microRNA misregulation have been proposed to explain the basis of somaclonal variation (Miguel and Marum, 2011; Rodriguez-Enriquez et al., 2011; Schellenbaum et al., 2008; Springer, 2013; Tanurdzic et al., 2008).

Genetic changes in tissue-cultured plants sometimes include modifications in chromosome numbers, which may be the result of spontaneous autopolyploidization (Chauvin et al., 2003; Meyer et al., 2009; Skof et al., 2007; van den Bulk et al., 1990). Spontaneous polyploidization was reported in several Solanum species, and it was found that polyploids obtained through spontaneous chromosome doubling were genetically more stable than those that were chemically induced (Chauvin et al., 2003; Skof et al., 2007). Chromosomal instability is often associated with disorganized cells as opposed to organized cultures from meristems (Bayliss, 1980), which were the explants used in this study. Furthermore, no growth regulators, which have been shown to affect the cytological status of cultured cells (Torrey, 1961), were added to the media in this study. However, whether this spontaneous autotetraploidization occurred in the original plant that produced this particular seed is not clear because endoreduplication could have taken place in the original plant or in the in vitro regeneration system (Meyer et al., 2009).
What is clear, however, is that this variation is heritable because flow cytometry analysis on progeny of the polyploid plants confirmed their tetraploid nature (Fig. $2 \mathrm{~B}-\mathrm{C}$ ). To the best of our knowledge, our study is the first to record spontaneous autotetraploidization in $S$. aethiopicum. Moreover, no record of the incidence of polyploid $S$. aethiopicum cultivars or wild cytotypes has been published.

Impact of autotetraploidy on morphological traits. Increased polyploidy resulted in significantly $(P=0.05)$ shorter tetraploid plants because they were $\approx 15 \%$ shorter than their diploid counterparts (Table 2). These results are in agreement with findings in several other species in which induced polyploidy generated shorter and more compact plants compared with control plants (Chen et al., 2006; Liu et al., 2007). Leaf length was not significantly $(P=0.05)$ affected by increased ploidy, but both leaf width and leaf index were (Table 2). Tetraploid plants had significantly wider leaves but lower leaf indices (length/width) than those of diploid plants (Fig. 3). Similar results were reported in other species such as Platanus acerifolia and Lagerstroemia indica (Liu et al., 2007; Zhang et al., 2010), and leaf index could be a useful indicator in the primary screening for ploidy levels (Wu et al., 2013).

Table 2. Comparison of morphological traits of diploid $(2 n=2 x=24)$ and tetraploid $(2 n=4 x=48)$ Solanum aethiopicum (PI 636107) plants.

\begin{tabular}{|c|c|c|c|c|}
\hline \multirow[b]{2}{*}{ Parameters } & \multicolumn{2}{|c|}{$2012^{z}$} & \multicolumn{2}{|c|}{$2013^{z}$} \\
\hline & Diploid & Tetraploid & Diploid & Tetraploid \\
\hline Plant height $(\mathrm{cm})^{\mathrm{y}}$ & $99.52 \pm 10.59 \mathrm{a}$ & $84.50 \pm 8.60 b$ & $102.47 \pm 11.21 \mathrm{a}$ & $86.30 \pm 5.16 b$ \\
\hline Leaf length $(\mathrm{cm})^{\mathrm{x}}$ & $22.56 \pm 0.85 \mathrm{a}$ & $23.84 \pm 1.34 \mathrm{a}$ & $23.54 \pm 0.65 \mathrm{a}$ & $23.66 \pm 1.25 \mathrm{a}$ \\
\hline Leaf width $(\mathrm{cm})^{\mathrm{x}}$ & $15.93 \pm 0.61 b$ & $20.11 \pm 1.50 \mathrm{a}$ & $16.06 \pm 1.52 \mathrm{~b}$ & $21.05 \pm 2.10 \mathrm{a}$ \\
\hline Leaf index (length/width) ${ }^{\mathrm{x}}$ & $1.43 \pm 0.06 \mathrm{a}$ & $1.21 \pm 0.04 \mathrm{~b}$ & $1.46 \pm 0.08 \mathrm{a}$ & $1.12 \pm 0.02 \mathrm{~b}$ \\
\hline
\end{tabular}

${ }^{\mathrm{z}}$ Means with different letters within a year and belonging to the same row are significantly different according to $t$ test $(P=0.05)$.

${ }^{y}$ For plant height, each value represents means \pm SE of 30 plants of each cytotype.

${ }^{x}$ For leaf dimensions, values represent the averages of 10 plants per cytotype and nine leaves (three $=$ lower leaves, three $=$ middle leaves, and three $=$ upper leaves) per plant.

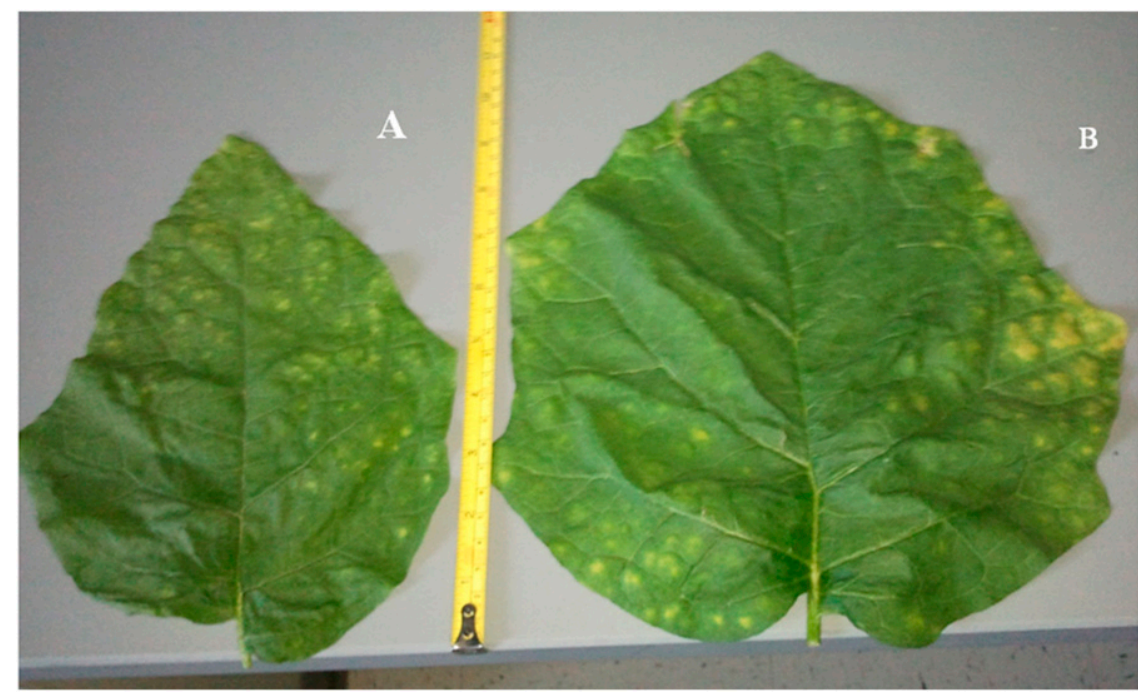

Fig. 3. Comparison between diploid $(2 n=2 x=24)$ and tetraploid $(2 n=4 x=48)$ cytotypes of Solanum aethiopicum L.(PI 636107) for leaf size: tetraploid (B) leaves were wider than diploid (A) leaves. 
Table 3. Comparison of pollen viability estimated through in vitro pollen germination and fruit traits of diploid $(2 n=2 x=24)$ and tetraploid $(2 n=4 x=48)$ Solanum aethiopicum L. (PI 636107) plants.

\begin{tabular}{|c|c|c|c|c|}
\hline \multirow[b]{2}{*}{ Parameters } & \multicolumn{2}{|c|}{$2012^{z}$} & \multicolumn{2}{|c|}{$2013^{z}$} \\
\hline & Diploid & Tetraploid & Diploid & Tetraploid \\
\hline In vitro pollen germination $(\%)^{y}$ & $60.92 \pm 3.00 \mathrm{a}$ & $36.47 \pm 6.36 \mathrm{~b}$ & $65.62 \pm 2.51 \mathrm{a}$ & $40.27 \pm 5.30 \mathrm{~b}$ \\
\hline Fruit numbers ${ }^{\mathrm{x}}$ & $155.85 \pm 8.72 \mathrm{a}$ & $154.89 \pm 10.2 \mathrm{a}$ & $143.62 \pm 6.32 \mathrm{a}$ & $144.95 \pm 8.22 \mathrm{a}$ \\
\hline Fruit length $(\mathrm{mm})^{\mathrm{x}}$ & $29.97 \pm 0.87 \mathrm{a}$ & $28.21 \pm 0.87 \mathrm{a}$ & $30.66 \pm 0.97 \mathrm{a}$ & $29.02 \pm 2.15 \mathrm{a}$ \\
\hline Fruit circumference $(\mathrm{mm})^{\mathrm{x}}$ & $135.25 \pm 4.67 \mathrm{a}$ & $121.917 \pm 3.60 \mathrm{~b}$ & $136.22 \pm 2.68 \mathrm{a}$ & $122.51 \pm 4.01 \mathrm{~b}$ \\
\hline Fruit fresh weight $(g)^{x}$ & $29.96 \pm 2.73 \mathrm{a}$ & $21.76 \pm 2.02 b$ & $33.22 \pm 1.62 \mathrm{a}$ & $23.16 \pm 3.04 \mathrm{~b}$ \\
\hline Fruit dry weight $(\mathrm{g})^{\mathrm{x}}$ & $3.15 \pm 0.31 \mathrm{a}$ & $2.21 \pm 0.26 \mathrm{~b}$ & $3.25 \pm 0.41 \mathrm{a}$ & $2.26 \pm 0.28 \mathrm{~b}$ \\
\hline Fruit solids $(\%)^{\mathrm{x}}$ & $10.39 \pm 0.21 \mathrm{a}$ & $9.91 \pm 0.30 \mathrm{a}$ & $11.13 \pm 1.21 \mathrm{a}$ & $10.95 \pm 0.23 \mathrm{a}$ \\
\hline
\end{tabular}

${ }^{\mathrm{z}}$ Means with different letters within a year and belonging to the same row are significantly different according to $t$ test $(P=0.05)$.

${ }^{\mathrm{y}}$ For in vitro pollen germination, 10 plants per ploidy level were chosen at random, and pollen viability was determined for the two cytotypes by prepping three flowers per plant and evaluating three slide locations per flower.

${ }^{\mathrm{x}}$ For these parameters, means are the averages of 30 plants per ploidy level.

Impact of autotetraploidy on pollen viability and fruit traits. Increased ploidy resulted in lower germination because in vitro pollen germination percentage was significantly $(P=0.05)$ higher in diploid than in tetraploid plants in both 2012 and 2013 (Table 3). In both years, the germination percentage dropped more than $24 \%$ in tetraploid plants. However, this did not seem to have any impact on fruit production because there was no significant difference $(P=0.05)$ between the two cytotypes in fruit numbers per plant (Table 3 ). Similarly, no difference was found between diploid and tetraploid plants for fruit length and fruit solids percentage, but tetraploid plants produced smaller fruit based on their smaller circumferences and reduced fresh and dry weights (Table 3 ) in contrast to results obtained by $\mathrm{Wu}$ et al. (2012) who reported a very significant increase in fruit size in induced autotetraploids of different genotypes of Actinidia chinensis. However, our results agree with those of Nilsson $(1950,1963)$ who also reported a reduction in fruit size in some induced tetraploid tomatoes, which, like $S$. aethiopicum, belong to the genus Solanum.

Here we report, for the first time, spontaneous autotetraploidization in S. aethiopicum. Compared with the diploids, the tetraploid plants were significantly shorter and had wider leaves and smaller fruits. Nevertheless, fruit production per plant was comparable. Tetraploid $S$. aethiopicum can be valuable for future breeding programs, in particular for those programs aiming to develop shorter, more compact plants. Some $S$. aethiopicum selections are cultivated for their edible leaves, so tetraploid plants producing large leaves would be desirable. Additionally, the genus Solanum is made up of over 2000 species that are often morphologically very different(Oyelana and Ugborogho, 2008), but interspecific hybridization for transfer of desirable genes often takes place (Daunay et al., 1993; Oyelana and Ugborogho, 2008; Toppino et al., 2008), so the availability of tetraploid S. aethiopicum can be useful in removing the hybridization barrier resulting from ploidy differences with other tetraploid Solanum species. Moreover, flow cytometry analysis of progeny from polyploid plants confirmed that the tetraploid trait is heritable (Fig. 2B-C); therefore, this new tetraploid $S$. aethiopicum line can be seed-propagated.

\section{Literature Cited}

Adneniji, O.T., P.M. Kusowa, and O.W.M. Reuben. 2012. Genetic diversity among accessions of Solanum aethiopicum L. groups based on morpho-agronomic traits. Plant Genet. Resour.; Characterization Util. 10:177-185.

Anaso, H.U. 1991. Comparative cytological study of Solanum aethiopicum Gilo group, Solanum aethiopicum Shum group and Solanum anguivi. Euphytica 53:81-85.

Ano, G., Y. Hebert, P. Prior, and C.M. Messiaen 1991. A new source of resistance to bacterial wilt of eggplants obtained from a cross: Solanum aethiopicum $\mathrm{L} \times$ Solanum melongena $\mathrm{L}$. Agronomie 11:555-560.

Aryavand, A.B., B. Ehdaie, B. Tran, and J.G Waines. 2003. Stomatal frequency and size differentiate ploidy levels in Aegilops neglecta. Genet. Resources Crop Evol. 50:175-182.

Bayliss, M.W. 1977. Factors affecting the frequency of tetraploid cell in a pre-dominantly diploid suspension culture Daucus carota. Protoplasma 92:109-115.

Bayliss, M.W. 1980. Chromosomal variation in plant tissue culture. Intl. Rev. Cytol. Suppl. 11A:113-144.

Chauvin, J.E., C. Souchet, J.P. Dantec, and D. Ellissèche. 2003. Chromosome doubling of $2 x$ Solanum species by oryzalin: Method development and comparison with spontaneous chromosome doubling in vitro. Plant Cell Tissue Organ Cult. 73:65-73.

Chen, L., Y. Wang, and M. Zhao. 2006. In vitro induction and characterization of tetraploid Lychnis senno Siebold et Zucc. HortScience 41:759-761.

Daunay, M.C., M.H. Chaput, D. Sihchakr, M Allot, F. Vedel, and G. Ducreux. 1993. Production and characterization of fertile somatic hybrids of eggplants (Solanum melongena L.) with Solanum aethiopicum L. Theor. Appl. Genet. 85:841-850.

Daunay, M.C., R.N. Lester, and H. Laterrot. 1991. The use of wild species for the genetic improvement of Brinjal egg-plant (Solanum melongena) and tomato (Lycopersicum esculentum), p. 389412. In: Hawkes, J.G., R.N. Lester, M. Nee, and N. Estrada (eds.). Solanaceae III: TaxonomyChemistry-Evolution. Royal Botanical Gardens Kew, London, UK.

Daunay, M.C., R.N. Lester, F. Rousselle-Bourgeois, and J.Y. Peron. 1995. Known and less known Solanum species for fresh market. Acta Hort. 412:293-296.

Hebert, Y. 1985. Comparative resistance of nine species of the genus Solanum to bacterial wilt (Psedomonas solanacearum) and nematode Meloidogyne incognita. Implications for breeding of aubergine ( $S$. melongena) in the humid tropical zone. Agronomie 5:27-32.

Jewell, D. C. and M.N. Islam-Faridi. 1994. Details of a technique for somatic chromosome preparation and C-banding of maize, p. 484-493. In: Freeling, M. and V. Walbot (eds.). The maize handbook. Springer-Verlag, New York, NY.

Kermani, M.J., V. Sarasan, A.V. Roberts, K. Yokoya, J. Wentworth, and V.K. Sieber. 2003. Oryzalin-induced chromosome doubling in Rosa and its effect on plant morphology and pollen viability. Theor. Appl. Genet. 107:1195-1200.

Lee, M. and R. Phillips. 1988. The chromosomal basis of somaclonal variation. Annu. Rev. Plant Physiol. Plant Mol. Biol. 39:413-437.

Lester, R.N., P.M.L. Jaeger, H.M. BleijendaalSpierings, H.P.O. Bleijendaal, and H.L.O. Holloway. 1981. African eggplants: A review of collection in West Africa. FAO/IBPGR Plant Genet. Resources Newslet. 81/82:17-26.

Lester, R.N. and A. Seck. 2004. Solanum aethiopicum L, p. 472-477. In: Grubben, G.J.H. and O.A. Denton (eds.). Plant resources of tropical Africa 2-Vegetables. PROTA Foundation/Backhuys Publishers/CTA, Wageningen, The Netherlands.

Liu, G., Z. Li, and M. Bao. 2007. Colchicineinduced chromosome doubling in Platanus acerifolia and its effect on plant morphology. Euphytica 157:145-154.

Mahfouz, M.N., M.T. deBoucand, and J.M. Gaultier. 1983. Caryological analysis of single cell clones of tobacco; relation between the ploidy and the intensity of callogenesis. Z. Pflanzenphysiol. 109:251-257.

Meyer, E.M., D.H. Touchell, and T.G. Ranney. 2009. In vitro shoot regeneration and polyploid induction from leaves of Hypericum species. HortScience 44:1957-1961.

Miguel, C. and L. Marum. 2011. An epigenetic view of plant cells cultured in vitro: Somaclonal variation and beyond. J. Expt. Bot. 62:3713-3725.

Murashige, T. and F. Skoog. 1962. A revised medium for rapid growth and bioassays with tobacco tissue cultures. Physiol. Plant. 15:473-497.

Nilsson, E. 1950. Some experiments with tetraploid tomatoes. Hereditas 36:181-204.

Nilsson, E. 1963. The potential fruit size of tetraploid tomato. Hereditas 49:237-240.

Oyelana, O.A. and R.E. Ugborogho. 2008. Phenotypic variation of $F_{1}$ and $F_{2}$ populations from three species of Solanum L. (Solanaceae). Afr. J. Biotechnol. 7:2359-2367.

Rizza, F., G. Mennella, C. Collonnier, D. Sihachkr, V. Kashyap, M.V. Rajam, M. Prestera, and G.L. Rotino. 2002. Androgenic dihaploids from somatic hybrids between Solanum melongena and S. aethiopicum group gilo as a source of resistance to Fusarium oxysporum f. sp. melongenae. Plant Cell Rpt. 20:1022-1032.

Rodriguez-Enriquez, J., H.G. Dickinson, and R.T Grant-Downton. 2011. MicroRNA misregulation: An overlooked factor generating somaclonal variation. Trends Plant Sci. 16:242-248.

Sakhanokho, H.F. and N. Islam-Faridi. 2013. Nuclear DNA content, base composition, and cytogenetic characterization of Christia obcordata. J. Amer. Soc. Hort. Sci. 138:205-209.

Sakhanokho, H.F. and K. Rajasekaran. 2010. Pollen biology of ornamental ginger (Hedychium spp. J. Koenig). Sci. Hort. 125:129-135.

Sari, N., K. Abak, and M. Pitrat. 1999. Comparison of ploidy level screening methods in watermelon: Citrullus lanatus (Thunb.) Matsum. and Nakai. Sci. Hort. 82:265-277.

Schellenbaum, P., V. Mohler, G. Wenzel, and B. Walter. 2008. Variation in DNA methylation patterns of grapevine somaclones (Vitis vinifera L.). BMC Plant Biol. 8:78. 
Skirvin, R.M., K.D. McPheeters, and M. Norton. 1994. Sources and frequency of somaclonal variation. HortScience 29:1232-1237.

Skof, S., B. Bohanec, D. Kastelec, and Z. Luthar. 2007. Spontaneous induction of tetraploidy in hop using adventitious shoot regeneration method. Plant Breed. 126:416-421.

Springer, N.M. 2013. Epigenetics and crop improvement. Trends Genet. 29:241-246.

Sunseri, F., G.B. Polignano, V. Alba, C. Lotti, V. Bisignano, G. Mennella, A.D. Alessandro, M. Bacchi, P. Riccardi, M.C. Fiore, and L. Ricciardi. 2010. Genetic diversity and characterization of African eggplant germplasm collection. Afr. J. Plant Sci 4:231-241.

Tanurdzic, M., M.W. Vaughn, H. Jiang, T.-J. Lee, R.K. Slotkin, B. Sosinski, W.F. Thompson, R.W. Doerge, and R.A. Martienssen. 2008. Epige- nomic consequences of immortalized plant cell suspension culture. PLoS Biol. 6:E302.

Toppino, L., G. Vale, and G.L. Rotino. 2008 Inheritance of fusarium wilt resistance introgressed from Solanum aethiopicum Gilo and Aculeatum groups into cultivated eggplants $(S$. melongena) and development of associated PCR-based markers. Mol. Breed. 22:237-250.

Torrey, J.G. 1961. Kinetin as trigger for mitosis in mature endomitotic plant cells. Expt. Cell Res. 23:281-299.

van den Bulk, R.W., H.L.M. Loffler, W.H. Lindhout, and M. Koornneef. 1990. Stomatal variation in tomato: Effect of explants sources and a comparison with chemical mutagenesis. Theor. Appl. Genet. 80:817-825.

Viehmannova, I., M. Travnickova, E. Spatenkova, M. Cerna, and P. Travnicek. 2012. Induced polyploidization and its influence on yield, morphological, and qualitative characteristics of microtubers in Ullucus tuberosus. Plant Cell Tiss. Org. Cult. 109:83-90.

Wu, J.-H., A.R. Fergusson, B.G. Murray, Y. Jia, P.M. Datson, and J. Zhang. 2012. Induced polyploidy dramatically increases the size and alters the shape of fruit in Actinidia chinensis. Ann. Bot. (Lond.) 109:169-179.

Wu, Y., W. Li, J. Dong, N. Yang, X. Zhao, and W. Yang. 2013. Tetraploid induction and cytogenetic characterization for Clematis herecleifolia. Caryologia: Intl. J. Cytol. Cytosyst. Cytogenet. 66:215-220.

Zhang, Q., F. Luo, L. Liu, and F. Guo. 2010. In vitro induction of tetraploids in crape myrtle (Lagerstroemia indica L.). Plant Cell Tissue Organ Cult. 101:41-47. 